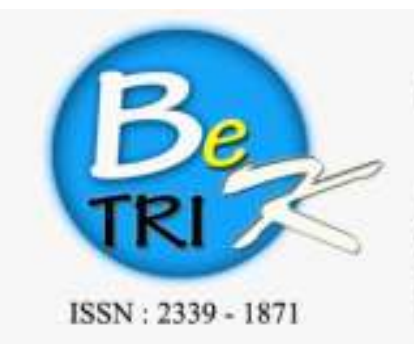

JURNAL ILMIAH BEETRIK

Editor Office : LPPM Sekolah Tinggi Teknologi Pagar Alam, Jn. Masik Siagim No. 75

Simpang Mbacang, Pagar Alam, SUM-SEL, Indonesia

Phone : +62 852-7901-1390.

Email : betrik@lppmsttpagaralam,ac.id / admin.jurnal@lppmsttpagaralam.ac.id

Website : hrtps://ejournal.lppmsttpagaralam.ac.id/index.php/betrik/index

\title{
RANCANG BANGUN APLIKASI EDUCATION GAME PEMBELAJARAN BAHASA INGGRIS BERBASIS MULTIMEDIA PADA SMP NEGERI 8 PAGARALAM
}

\author{
Siti Aminah \\ Program Studi Teknik Informatika Sekolah Teknologi Pagaralam \\ Jalan Masik Siagim No. 75 Simpang Mbacang Kec.Dempo Tengah Pagar Alam \\ Sur-el: gosupeta@gmail.com
}

\begin{abstract}
Improving competitiveness and competitive advantage of all sectors, demanding human beings to have a hinger quality capability in human resources, science and tecnology, so that people can survive in their life. One means that must be mastered in facing the era of globalization is the ability to communicate with english, so that English is highly emphasized mastery in indonesia. Research multimedia software learning english at SMP Negeri 8 Pagaralam aims to develop and evaluate multimedia software learning english for junior high school student. The methods used include concept, design, material collecting, assembly, testing and distribution. Education game applications are expected to help teachers provide materials to students by learning while playing to improve student learning in english lessons. This application is very effective and can be used as a tool that contains materials and practice of english for students in english language learnig.
\end{abstract}

Keyword : Multimedia Learning, english, student SMP

Abstrak : Meningkatkan daya saing dan keunggulan kompetitif dari semua sektor, menuntut manusia untuk mempunyai kemampuan yang semakin berkualitas baik dalam bidang Sumber Daya Manusia (SDM), ilmu maupun teknologi , agar manusia tetap mampu bertahan dalam kehidupannya. salah satu sarana yang harus dikuasi dalam menghadapi era globalisasi tersebut adalah kemampuan berkomunikasi dengan Bahasa Inggris, sehingga Bahasa Inggris sangat ditekankan penguasaannya di Indonesia. Penelitian multimedia pembelajaran Bahasa Inggris pada SMP Negeri 8 Pagaralam ini bertujuan untuk mengembangkan dan mengevaluasi perangkat lunak multimedia pembelajaran Bahasa Inggris untuk siswa Sekolah Menengah Pertama. Metode yang dipakai meliputi Concept, Design, Material Collecting, Assembly, Testing dan Distribution. Aplikasi Education game diharapkan dapat membantu guru memberikan materi kepada siswa dengan cara belajar sambil bermain untuk meningkatkan belajar siswa dalam pelajaran Bahasa Inggris. Aplikasi ini dibangun dengan konsep multimedia yang ini sangat efektif dan dapat digunakan sebagai alat bantu yang berisi materi dan soal latihan Bahasa Inggris untuk siswa didalam pembelajaran Bahasa Inggris.

Kata Kunci : Multimedia pembelajaran, Bahasa Inggris, Siswa SMP 


\section{PENDAhUluan}

Pendidikan memiliki peran yang sangat penting dimasa anak-anak, karena perkembangan kepribadian, sikap mental dan intelektual dibentuk pada usia sekarang. Masa anak-anak merupakan masa yang tepat untuk memulai memberikan berbagai stimulus agar siswa dapat berkembang secara optimal. Pendidikan berasal dari kata didik, atau mendidik yang berarti memelihara dan membentuk latihan. Pendidikan adalah sebuah proses pembelajaran yang didapat oleh setiap manusia, dalam hal ini adalah peserta didik, tujuannya adalah untuk membuat siswa itu paham, mengerti serta mampu berpikir lebih kritis. Pendidikan dapat dirumuskan sebagai tuntunan pertumbuhan manusia sejak lahir hingga tercapai kedewasaan jasmani dan rohani, dalam interaksi alam dan lingkungan masyarakatnya.

Menurut (Arizal, 2011), kemajuan dibidang teknologi dan persaingan yang semakin ketat, agar dapat menguasai Bahasa Inggris yang merupakan bahasa internasional. Oleh sebab itu, pendidikan Bahasa Inggris perlu dikenalkan dan dipelajari. Karena Bahasa Inggris bukan merupakan bahasa mereka, sehingga mereka tidak terbiasa mendengar atau mengucapkan pelafalan dalam Bahasa Inggris. Penulis memilih siswa SMP sebagai target user karena mempertimbangkan kesulitan proses pembelajaran secara teoritis pada siswa mengingat siswa lebih suka bermain. Dengan adanya education game diharapkan dapat mengatasi masalah tersebut. Masuknya game dalam proses belajar, melahirkan suasana yang menyenangkan karena siswa tersebut dapat mengendalikan kecepatan belajar sesuai dengan kemampuan. Lalu dengan adanya gambar dan suara yang muncul membuat siswa tidak merasa bosan, sebaliknya akan menumbuhkan rasa ingin tahu para siswa.

Menurut teori education game adalah media pembelajaran yang membuat siswa bermain sambil belajar, dimana siswa tidak merasa terbebani dalam menguassai materi, karena mereka merasa sedang bermain-main dengan game yang merupakan permainan yang mereka sukai sehari-hari, sehingga materi dapat terserap dengan kemauan siswa sendiri. Siswa justru termotivasi untuk belajar agar dapat mengerjakan permainan dengan baik.

Berdasarkan penelitian (Dony, 2013) Aplikasi Game Geografi Berbasis Multimedia Interaktif (Studi Kasus Siswa Kelas IX SMPN 1 Rao). Penelitian ini bertujuan untuk menunjang pembelajaran terhadap siswa, terutama yang berhubungan pada mata pelajaran hafalan yaitu geografi. Selama ini media pembelajaran yang digunakan bersifat monoton dan guru mengajar menggunakan metode konvensional, sehingga proses pembelajaran yang tidak efektif ini dapat ditanggulangi dengan menggunakan media pembelajaran interaktif. Game edukasi ini digunakan sebagai salah satu media pembelajaran yang memiliki pola pembelajaran learning by doing. 
Berdasarkan penelitian (Rohwati, 2012) Penggunaan Education Game Untuk Meningkatkan Hasil Belajar IPA Biologi Konsep Klasifikasi Mahluk Hidup Tujuan penelitian ini untuk meningkatkan hasil belajar IPA Biologi tentang klasifikasi makhluk hidup bagi siswa kelas VII B SMP N 1 Wonosobo yang dilaksanakan pada semester 1 tahun 2009/2010. Pada siklus I diketahui hasil belajar meningkat tajam dari yakni dari 55,03 menjadi 81,71. Pada akhir siklus II hasil belajar meningkat menjadi 87,57 . Jadi pembelajaran menggunakan education game dapat meningkatkan hasil belajar, keaktifan siswa dalam pembelajaran, penguasaan bahasa serta penggunaan ICT dalam pembelajaran

Sekolah Menengah Pertama Negeri 8 Pagaralam merupakan salah satu Sekolah yang masuk dalam daftar Sekolah Model yang ada di Kota Pagaralam yang berdiri pada tahun 2003. SMP Negeri 8 dilengkapi dengan Teknologi pendukung seperti komputer, jaringan internet serta $L C D$ Proyektor dan Lab Komputer, untuk mempermudah menerapkan aplikasi education game dengan memanfaatkan teknologi untuk pembelajaran agar dapat meningkatkan pemahaman siswa terhadap materi pelajaran Bahasa Inggris.

Tujuan penelitian untuk merancang dan membangun aplikasi Education Game Pembelajaran Bahasa Inggris berbasis multimedia interaktif dengan menggunakan adobe flash cs6 di SMP N.8 Pagaralam

\section{METODE PENELITIAN}

\subsection{Pengertian Rancang Bangun}

Menurut (Jogiyanto, 2005) rancang bangun (desain) adalah tahap dari setelah analisis dari siklus pengembangan sistem yang merupakan pendefinisian dari kebutuhankebutuhan fungsional, serta menggambarkan bagaimana suatu sistem dibentuk yang dapat berupa penggambaran, perencanaan dan pembuatan sketsa atau pengaturan dari beberapa elemen yang terpisah ke dalam satu kesatuan yang utuh dan berfungsi, termasuk menyangkut mengkonfigurasikan dari komponenkomponen perangkat keras dan perangkat lunak dari suatu sistem.

\subsection{Pengertian Aplikasi}

Menurut (jogiyanto, 2005) aplikasi adalah penggunaan dalam suatu komputer, intruksi (instruction) atau pernyataan (statement) yang disusun sedemikian rupa sehingga komputer dapat memproses input menjadi output. Menurut kamus besar Bahasa Indonesia (2005), “Aplikasi adalah penerapan dari rancang sistem untuk mengolah data yang menggunkan aturan atau ketentuan bahasa pemrograman tertentu".

Menurut Jogiyanto (2004) Aplikasi merupakan program yang berisikan perintahperintah untuk melakukan pengolahan data. Dan aplikasi secara umum adalah suatu proses dari cara manual yang ditransformasikan ke komputer dengan 
membuat sistem atau program agar data diolah lebih berdaya guna secara optimal.

\subsection{Pengertian Education Game}

Menurut (Ghea, 2012) Education game adalah salah satu jenis media yang digunakan untuk memberikan pengajaran, menambah pengetahuan penggunanya melalui suatu media unik dan menarik. Jenis ini biasanya ditujukan untuk anak-anak, maka permainan warna sangat diperlukan disini bukan tingkat kesulitan yang dipentingkan.

Game adalah kata Bahasa Inggris yang berarti permainan atau pertandingan, atau bisa diartikan sebagai aktifitas terstruktur yang biasanya dilakukan untuk bersenang-senang. Menurut Anggra (Zulfadli Fahrul Rozi, 2010) game atau permainan adalah sesuatu yang dapat dimainkan dengan aturan tertentu sehingga ada yang menang dan ada yang kalah, biasanya dalam konteks tidak serius. Macam-macam game, antara lain:

\section{a.Aksi}

Game ini macam game yang paling populer. Game jenis ini membutuhkan kemampuan refleks pemain.

b. Aksi petualangan

Game ini memadukan game play aksi petualangan. Contohnya pemain diajak untuk menyelusuri gua bawah tanah sambil mengalahkan musuh atau menyeberangi sungai.

c.Simulasi, Konstruksi dan Manajemen

Pemain dalam game ini diberi keleluasaan untuk membangun dan suatu proyek tertentu dengan bahan baku yang terbatas.

d. Olahraga

Geme ini membawa olahraga ke dalam sebuah komputer atau konsol. Biasanya gameplay dibuat semirip mungkin dengan kondisi olahraga yang sebenarnya.

e.Puzzle

Geme puzzle menyajikan teka-teki, menyamakan warna bola, perhitungan matematika, menyusun balok, atau mengenal huruf dan gambar.

\section{f.Permainan Kata}

Word game sering dirancang untuk menguji kemampuan dengan bahasa atau untuk mengeksplorasi sifatsifatnya. Word game umumnya digunakan sebagai sumber hiburan, tetapi telah dibuktikan untuk melayani suatu tujuan pendidikan juga

Jadi, education game adalah permainan yang dirancang khusus untuk mengajarkan siswa dalam suatu pelajaran tertentu dengan konsep bermain sambil belajar.

\subsection{Pengertian Multimedia}

Menurut (Suyanto, 2005) Multimedia merupakan kombinasi dari komputer dan video. Rosch (1996) atau multimedia secara umum merupakan kombinasi tiga elemen,yaitu suara gambar dan teks. McCormick (1996). atau multimedia adalah kombinasi dari paling sedikit dua media input atau output dari data, 
media ini dapat audio, animasi, video, teks, grafik dan gambar (Turban dkk, 2002).

Definisi yang lain dari multimedia, yaitu dengan menempatkan dalam konteks, seperti yang dilakukan oleh Hofstetter (2001) multimedia adalah pemanfaatan komputer untuk membuat dan menggabungkan teks, grafik, audio, gambar bergerak (video dan animasi) dengan menggabungkan link dan tool yang memungkinkan pemakai melakukan navigasi, berinteraksi, berkreasi dan berkomunikasi.

Kegunaan multimedia antara lain adalah:

1. Pada bidang pemasaran, multimedia digunakan untuk persentasi atau mempromosikan produk atau gagasan yang ingin dipasarkan dalam bentuk yang lebih jelas dan memikat.

2. Pada bidang pendidikan, multimedia digunakan untuk memvisualisasikan pelajaran-pelajaran yang sulit diterangkan dengan cara konvensional

3. Pada bidang hiburan multimedia digunakan dalam program-program permainan untuk membentuk suasana yang lebih menarik dan interaktif.

4. Pada bidang perfilman, multimedia digunakan untuk pembuatan film animasi, pembuatan film kartun sehingga film tersebut menjadi efektif dan efisien

5. Pada bidang kesehatan, multimedia dapat mendukung pelayanan dan fasilitas sistem kesehatan yang mempromosikan jasa dan penelitian lewat situs Web Sistem Kesehatan.

\subsection{Jenis-jenis Multimedia}

\section{Multimedia interaktif}

Pengguna atau user dapat mengontrol secara penuh mengenai apa dan kapan elemen multimedia akan ditampilkan atau dikirimkan. Contoh : Game, Cd interaktif, aplikasi program dll.

2. Multimedia hiperaktif

Mempunyai struktur dengan elemenelemen terkait yang dapat diarahkan oleh pengguna melalui tautan (link) dengan elemen-elemen multimedia yang ada. Contoh : world wide web, web site, mobile banking, game online dll.

\section{Multimedia linear}

Adalah jenis multimedia yang berjalan lurus. Multimedia jenis ini bisa dilihat pada semua jenis film, tutorial video dll

4. Multimedia presentasi pembelajaran Multimedia presentasi pembelajaran adalah alat bantu guru dalam proses pembelajaran dikelas dan tidak menggantikan guru secara keseluruhan. Contohnya Microsoft Power Point.

5. Multimedia pembelajaran mandiri Multimedia pembelajaran mandiri adalah software pembelajaran yang dapat dimanfaatkan oleh siswa secara mandiri harus dapat memadukan explicit knowladge dan tacit knowladge, mengandung fitur assemen untuk latihan, ujian dan simulasi termasuk 
tahapan pemecah masalah. Contohnya macromedia authorware atau adobe flash.

6.

\section{Hypermedia}

Dokumen berurut non terdiri dari teks, audio, informasi visual disimpan dalam komputer contohnya adalah dengan pembelajaran menggunakan link pada sebuah web.

\subsection{Metode Pengembangan Sistem}

Dalam pengembangan sistem ini metode pengembangan mengunakan metode pengembnagan sistem multimedia Menurut Sutopo (2003), metode pengembangan sistem multimedia terdiri atas enam tahapan yaitu concept, design, material colleting, assembly, testing, distribution, tahpan multimedia ini dapat di jelaskan sebagai berikut:

\section{a. Concept}

Tahap concept ini analisis kebutuhan dilakukan untuk mengetahui kebutuhan aplikasi multimedia pembelajaran bahasa inggris dengan melakukan studi pendahuluan dengan guru kelas Tujuh SMP Negeri 8 Pagaralam.

\section{b.Design}

Pada tahap ini dilakukan penentuan spesifikasi secara rinci mengenai arsitektur proyek, gaya, dan kebutuhan material untuk proyek. Spesifikasi dibuat cukup rinci sehingga pada tahap berikutnya yaitu material collecting dan assembly tidak diperlukan keputusan baru, tetapi menggunakan apa yang sudah ditentukan pada tahap design.

a. Storyboard

penggunaan storyboard bermanfaat bagi pembuat multimedia, pemilik multimedia dan sponsor. Bagi pengembang dan pemilik multimedia ,storyboard merupakan visual test yang pertama-tama dari gagasan dimana secara keseluruhan dapat dilihat apa yang akan disajikan.

\section{b. Flowchart View}

Flowchart view disebut juga diagram tampilan adalah diagram yang memberikan gambaran alir dari satu scene (tampilan) kescene lainnya. dalam flowchart dapat dilihat komponen yang terdapat dalam suatu scane dengan penjelasan yang diperlukan

\section{c. Material Colleting}

Material collecting adalah tahap dimana dilakukan pungumpulan bahan yang sesuai dengan kebutuhan. Pengumpulan bahan ini antara lain buku ajaran pada kelas tujuh dengan materi belajar sederhana seperti reading, writing, listening, game puzzle dan tebak gambar . Bahan untuk pembuatan multimedia diantara lain gambar, clip art dan suara yang akan digunakan untuk membuat konten multimedia. Termasuk tombol, foto, animasi, soal test, video yang akan digunakan tiap scane aplikasi. Bahan 
tersebut dikumpulkan dan nantinya akan menjadi Aplikasi Multimedia Pembelajaaran Bahasa Inggris.

\section{d. Assembly}

Tahap assembly (pembuatan) merupakan tahap dimana seluruh objek multimedia dibuat. Pembuatan aplikasi berdasarkan storyboard, flowchart view, struktur navigasi, atau diagram objek yang berasal dari tahap design.

Langkah awal yang dilakukan pada tahap ini adalah membuat kerangka atau background seluruh menu-menu aplikasi dimultimedia. Kemudian memberi atributatribut berupa kata-kata warna tiap menu kemudian membuat tombol-tombol yang dibutuhkan pada menu multimedia.

Kemudian, pengisian materi didalam setiap menu dalam multimedia pembelajaran yang dibangun. Contoh penambahan antara lain tombol dapat ditekan untuk memunculkan sesuatu atau berpindah kemenu selanjutnya, penyatuan seluruh objek dalam game dan penambahan tersebut menggunakan Aplikasi Adobe Flash Cs6.

\section{e. Testing}

Pada tahap testing dilakukan setelah tahap assembly selesai. Tahap testing dilakukan dengan tahap sistem multimedia oleh pengembang. Pada tahap ini akan dilakukan pengujian yang dibagi menjadi 2 bagian, yaitu :
1. Alpha testing software yang digunakan sebagaimana mestinya dengan software yang tetap mengawasi apbila terjadi kesalahan, atau dengan kata lain uji coba dilakukan dalam lingkungan yang terkontrol.

2. Beta testing dilakukan dari sisi end user baik seorang maupun beberapa orang untuk mengetahui apakah multimedia pembelajaran yang dibangun telah sesuai dengan kebutuhan.

\section{f. Distribution}

Tahap distribution merupakan tahap evaluasi terhadap suatu produk multimedia dilakukan. Dengan dilakukan evaluasi, akan dapat dikembangkan sistem yang lebih baik dikemudian hari.

Multimedia pembelajaran Bahasa Inggris ini akan didistribusikan dalam format flash yaitu file,.swf.

\subsection{Rencana Usulan Perancangan}

\subsubsection{Sistem Yang Berjalan}

Sebelum melakukan perancangan terhadap suatu multimedia pembelajaran, terlebih dahulu akan dianalisa sistem pembelajaran yang sedang berjalan dalam penyampaian materi mata pelajaran Bahasa Inggris pada siswa kelas VII di SMP Negeri 8 Pagaralam. Hal ini dilakukan untuk mengetahui dan mempelajari kelemahan sistem pembelajaran tersebut dan masalah yang dihadapi, dimana saat ini dalam 
penyampaian materi Bahasa Inggris masih menggunakan media konvensional, yaitu menggunakan papan tulis dan buku sebagai alat bantu ajar dalam penyampaian materi Bahasa Inggris. Maka sistem pembelajaran dapat di lihat dalam gambar berikut

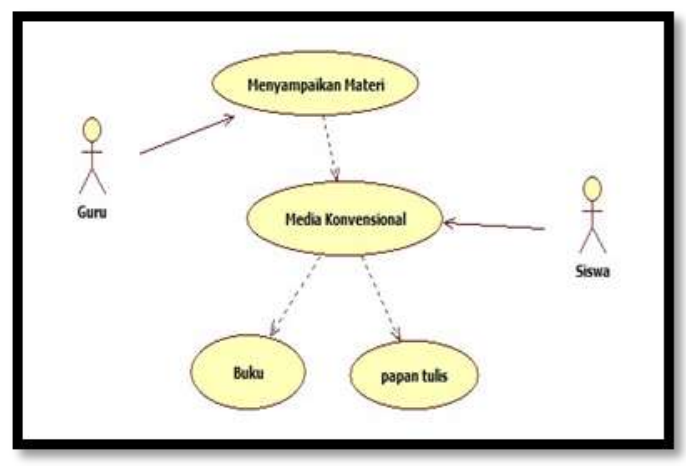

Gambar 1. Sistem Yang Berjalan

\subsubsection{Sistem Yang Diusulkan}

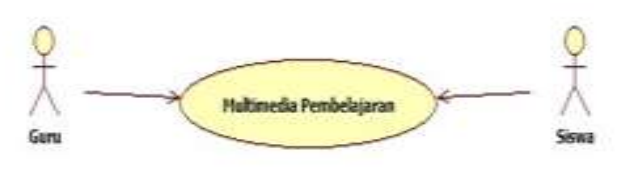

Gambar 2. Sistem Yang Diusulkan

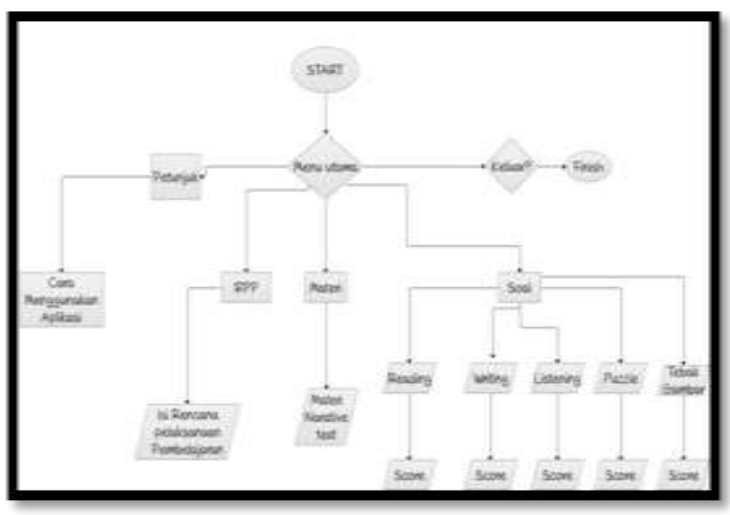

Gambar 3. Flowchart Sistem Yang Diusulkan
Berikut adalah tampilan flowchart sistem yang diusulkan yang dapat dilihat pada gambar 3.3 ketika kita mulai aplikasi pada menu utama terdapat 5 sub menu pilihan yaitu menu petunjuk, RPP, materi, soal dan keluar. Pada menu petunjuk berisi tentang cara mengunakan aplikasi, pada menu RPP berisikan materi tentang rencana pelaksanaan pembelajaran pada SMP NEGERI 8 Pagaralam. Dan pada menu materi berisikan materi tentang narative text untuk menjawab soal yang berupa reading, writing, dan listening. Didalam menu soal terdapat 5 sub menu pilihan untuk menjawab soal dalam bentuk reading, writing, listening, puzzle dan tebak gambar yang menghasilkan skor. Pada menu keluar untuk mengakhiri aplikasi yang dijalankan.

\subsubsection{Rencana Usul Perancnagan Sistem}

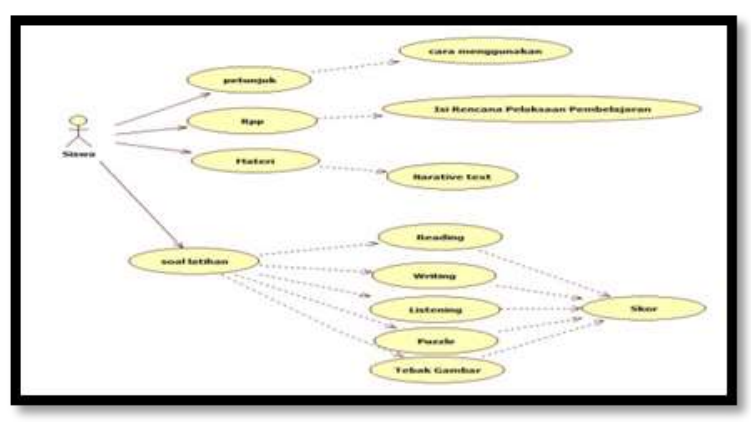

Gambar 4. Perancangan sistem

\subsection{Rancangan Tampilan}

\subsubsection{Rancangan Halaman utama}

Berdasarkan Gambar 3.5 pada saat program pertama kali dijalankan maka user dihadapkan pada tampilan utama aplikasi. 


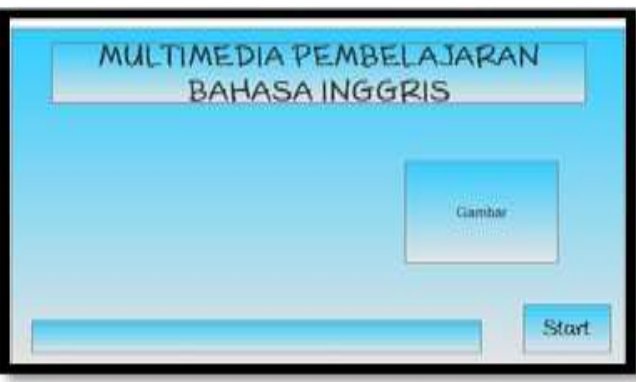

Gambar 5. Tampilan awal

\subsubsection{Tampilan Menu Pilihan}

Berdasarkan gambar dibawah tampilan menu utama yang terdiri dari 5 (Lima) pilihan menu, yaitu menu petunjuk, menu RPP, menu materi, menu soal dan menu keluar.

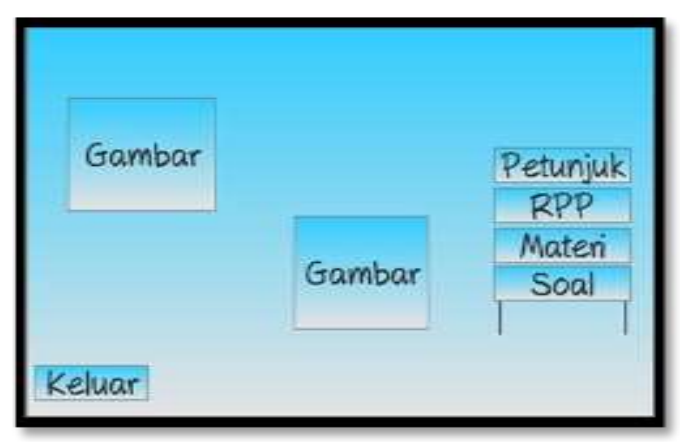

Gambar 6. Tampilan menu pilihan

\subsubsection{Tampilan Menu Petunjuk}

Pada tampilan menu petunjuk gambar 7. berisikan cara mengunakan aplikasi.

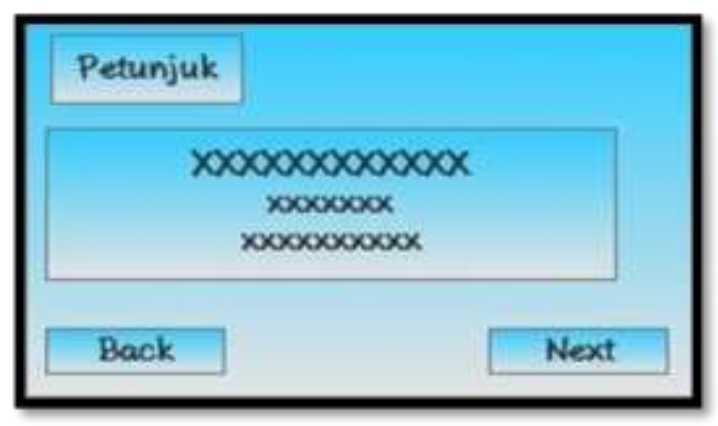

Gambar 7. Tampilan cara bermain

\subsubsection{Tampilan Menu RPP (Rencana Pelaksanaan Pembelajaran)}

Ketika siswa mengklik menu RPP terdapat 1 (satu sub menu) yang berisikan tentang Standar Kompetensi. Seperti gambar di bawah ini.

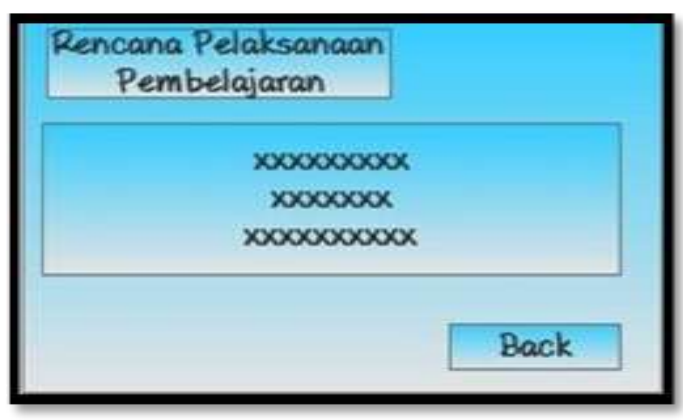

Gambar 8. Tampilan menu RPP

\subsubsection{Tampilan Menu Materi}

Pada menu materi berisikan materi tentang reading, writing dan listening untuk menjawab soal-soal.

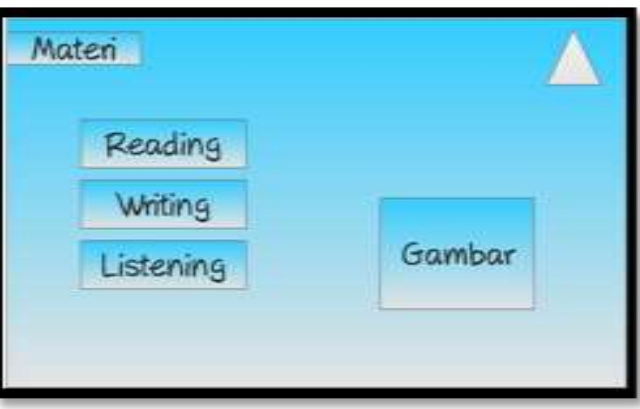

Gambar 9 Tampilan menu materi

\subsubsection{Tampilan Menu Soal}

Di menu tampilan soal terdapat 5 sub menu pilihan untuk mengerjakan soal yaitu reading, writing, listening, puzzle dan tebak gambar. 


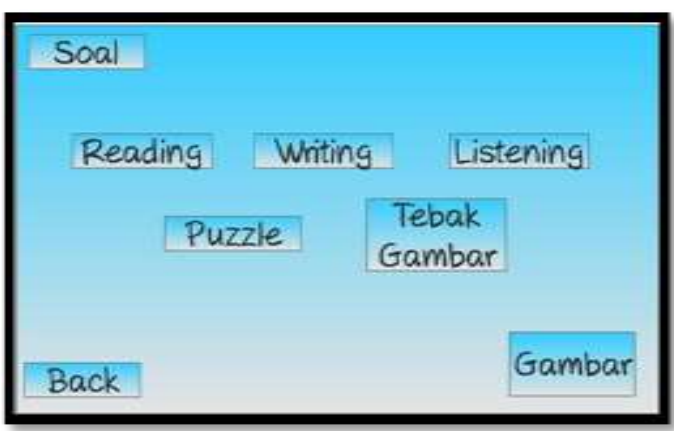

Gambar 10. Tampilan Menu Soal

\subsubsection{Tampilan Soal Reading}

Sebelum mengerjakan soal reading siswa harus mengisi nama, dapat dilihat gambar dibawah ini.

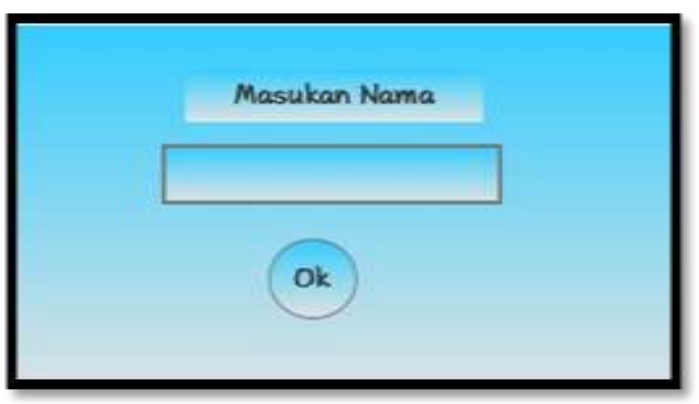

Gambar .11 Tampilan Input Nama

Pada gambar 12 dibawah ini menu reading berisikan soal tentang Bahasa Inggris kelas VII pada SMP Negeri 8 Pagaralam. Sebelum mengerjakan soal siswa harus membaca materi yang disamping. Soal berbentuk pilihan ganda.

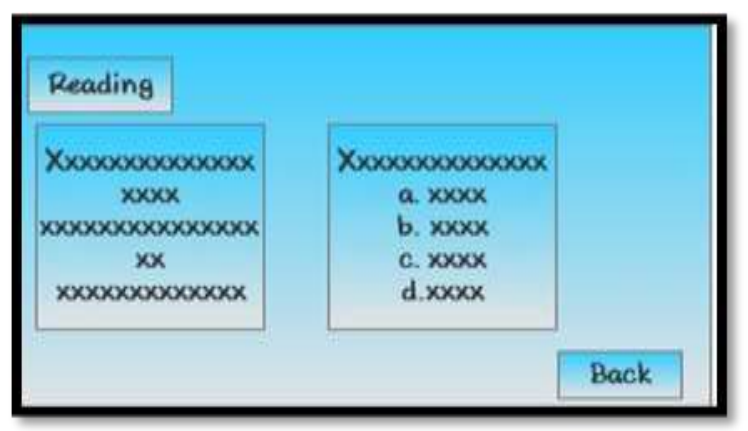

Gambar. 12 Tampilan Soal Reading

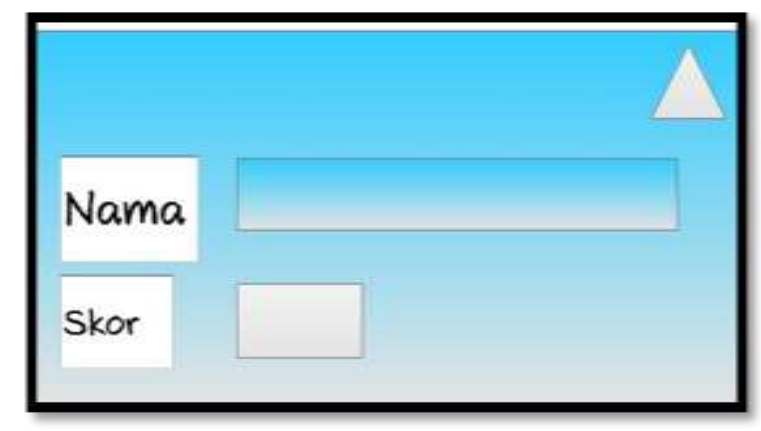

Gambar. 13 Tampilan Skor

\subsubsection{Tampilan Soal Writing}

Sebelum mengerjakan soal writing siswa harus mengisi nama, dapat dilihat gambar dibawah ini.

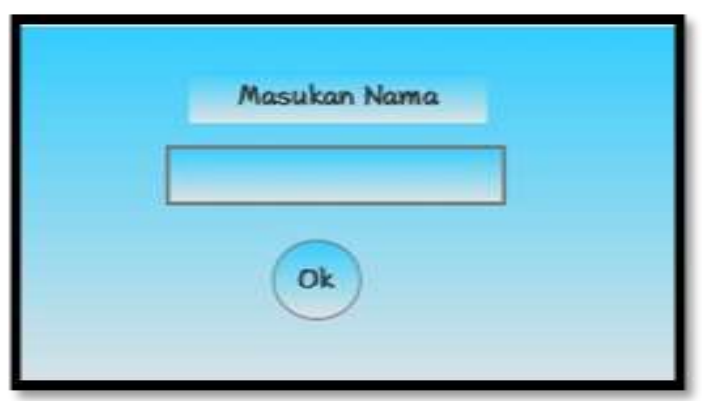

Gambar . 14 Tampilan Input Nama

Pada gambar 15 tampilan menu soal writing berisikan soal Bahasa Inggris untuk siswa kelas VII SMP Negeri 8 Pagaralam dengan cara mengisi kotak-kotak yang kosong dengan mengetik.

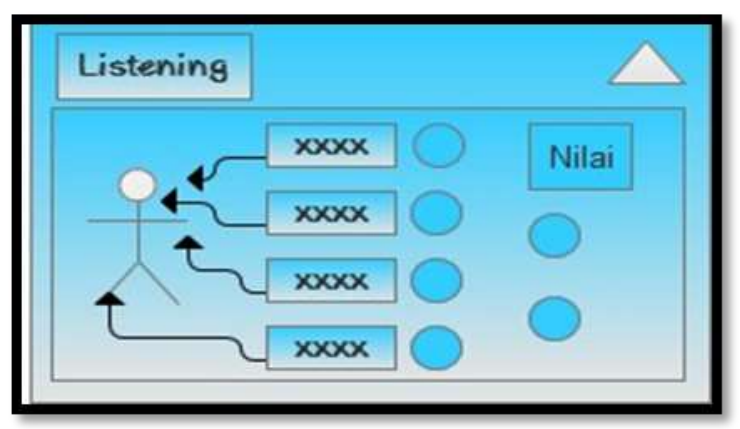

Gambar. 15 Soal Listening 


\subsubsection{Tampilan Menu Listening}

Sebelum mengerjakan soal

Listening siswa harus mengisi nama, dapat dilihat gambar dibawah ini.

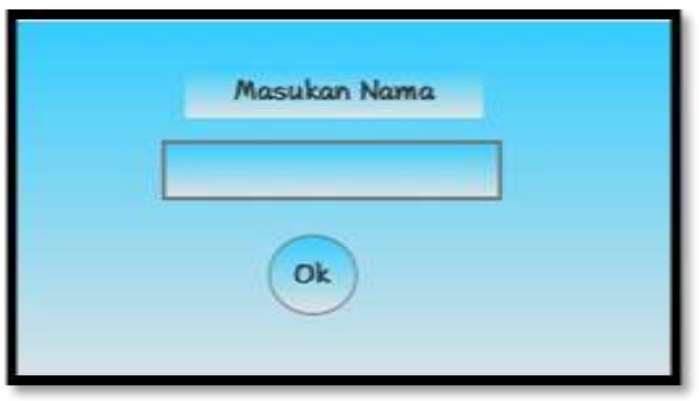

Gambar 16. Tampilan Input Nama

Pada gambar 17 tampilan menu listening berisikan soal bahasa inggris untuk siswa kelas VII SMP Negeri 8 Pagaralam dengan mendengarkan soal yang ada diteks dan menjawab soal pilihan ganda.

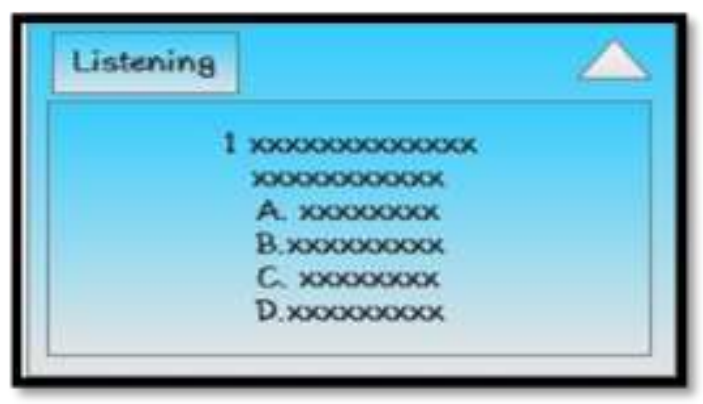

Gambar 17 Tampilan Soal Listening

Setelah menjawab semua soal siswa dihadapkan pada halaman skor, hasil akhir dari soal listening

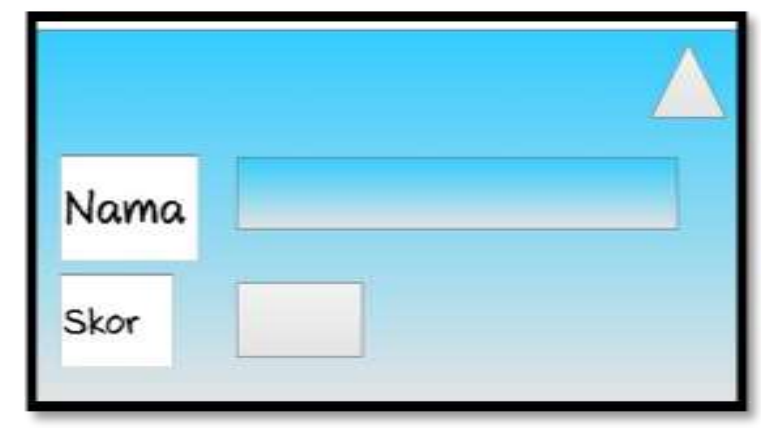

Gambar . 18 Tampilan Skor

\subsubsection{Tampilan Puzzle}

Sebelum mengerjakan game puzzle siswa harus mengisi nama, dapat dilihat gambar dibawah ini.

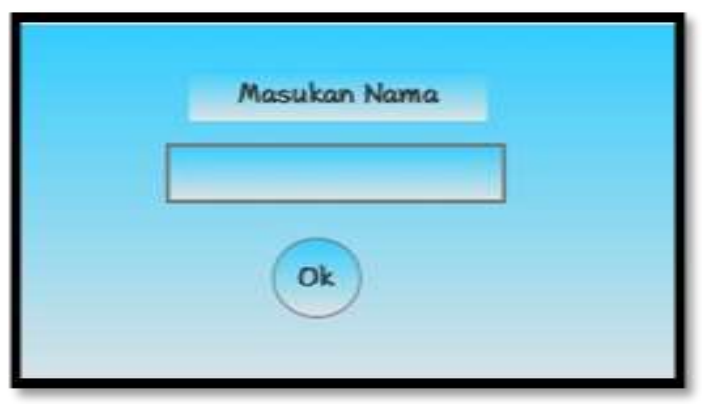

Gambar 19 Tampilan Input Nama

Pada tampilan menu game puzzle. Siswa harus meletakan kepingan gambar dengan cepat. Karena ada waktu di setiap kepingan gambar terdapat skor, satu gambar 10 jika kepingan gambar yang harus disusun 10 nilai yang akan didapat siswa adalah 100 .

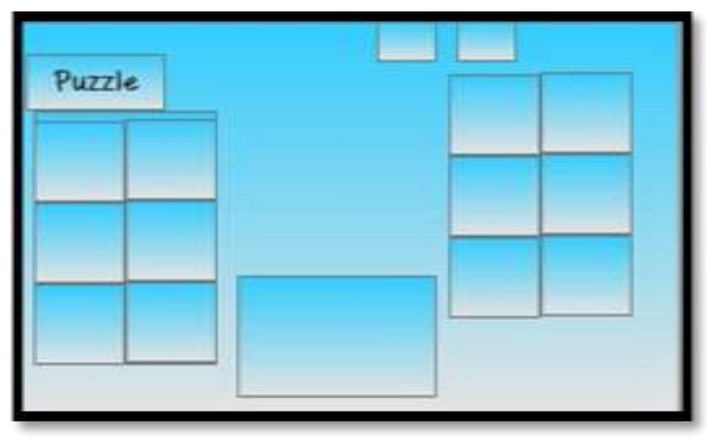

Gambar. 20 Tampilan Game puzzle 


\section{HASIL DAN PEMBAHASAN}

Hasil dari rancangan multimedia pembelajaran yang telah dibuat dapat dijalankan sesuai yang telah diharapkan. Program yang sudah dibuat diantaranya adalah pembelajaran Bahasa Inggris dengan menggunakan game puzzle, tebak gambar dan soal pilihan ganda materi untuk kelas VII SMP NEGERI 8 Pagaralam. Hasil dari perancangan multimedia pembelajaran ini memiliki beberapa keunggulan yaitu dengan program ini siswa dapat memahami materi dan mengerjakan soal dengan mudah. Dari segi tampilan multimedia lebih menarik dengan tampilan warna yang bagus dan banyak disukai banyak siswa karena dirancang secara interaktif. Tampilan pada menu utama di desain dan semenarik mungkin.

Aplikasi multimedia pembelajaran bahasa inggris di SMP Negeri 8 Pagaralam yang dihasilkan dapat dioperasikan berupa Aplikasi multimedia yaitu berisi halaman petunjuk, halaman RPP, halaman materi dan halaman soal. Siswa dapat mengoperasikan multimedia dengan memilih menu-menu tersebut dan terdapat materi pelajaran untuk kelas Tujuh SMP Negeri 8 Pagaralam. Seperti pada Menu Materi berisikan materi tentang reading, writing dan listening. Dalam menu soal terdapat 5 pilihan bentuk soal yaitu reading, writing, listening, puzzle, dan tebak gambar.

\subsection{Perangkat kebutuhan sistem}

Untuk dapat menjalankan Aplikasi Pembelajaran Bahasa Inggris Berbasis
Multimedia ini maka membutukan perangkat laptop atau komputer sebagi berikut:

1.Perangkat keras (Hardware) yang terdiri dari

a. Processor intel

b. Hardisk $500 \mathrm{~GB}$

c. RAM $2 \mathrm{~GB}$

d. Speaker

2. Perangkat Lunak (Software)

e. Windows 7

f. Macromedia Flash 8 / Adobe Flash Cs6

g. Adobe Photoshop Cs6

h. Axure RP Pro 7.0

i. StarUML

\subsection{Pembahasan}

Berikut ini adalah pembahasan dari hasil uji coba atau testing education game pembelajaran Bahasa Inggris. Berikut ini adalah tampilan dari masing-masing menu yang ada pada game puzzle berbasis multimedia

\subsection{Penyajian Desain Menu Utama}

\subsubsection{Halaman Menu Utama}

Sebelum siswa akan memulai memainkan Aplikasi ini siswa akan dihadapkan dengan menu loading. Desain halaman utama dapat dilihat pada gambar dibawah ini. 


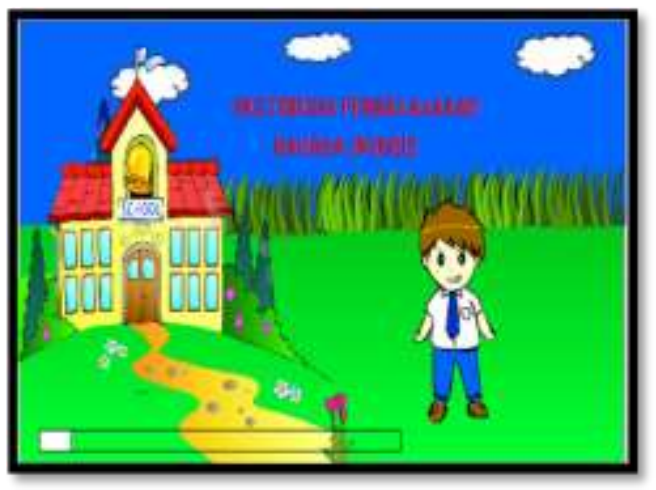

Gambar 21 Desain Menu Utama

\subsubsection{Halaman Menu Pilihan}

Tampilan pada saat siswa akan memulai dan ada beberapa menu pilihan yaitu, menu petunjuk, menu RPP, menu Materi, menu Soal dan keluar.

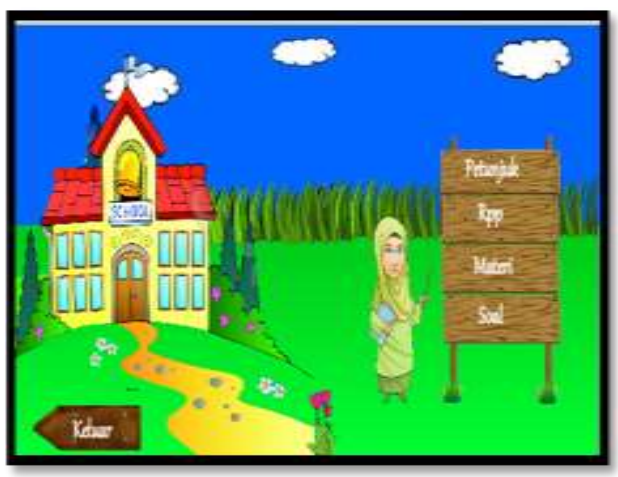

Gambar 22. menu pilihan

\subsubsection{Halaman Menu Petunjuk}

Pada halaman petunjuk di halaman utama game yang didapat pada tampilan ini adalah tentang cara bermain, dapat dilihat pada gambar dibawah ini.

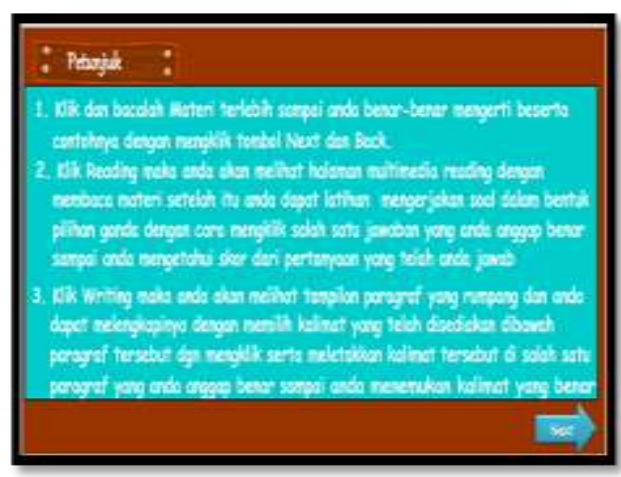

Gambar 23. menu petunjuk

\subsubsection{Halaman Menu RPP}

Didalam menu RPP terdapat rencana kegiatan pembelajaran yang di berikan kepada siswa. Dapat dilihat pada gambar dibawah ini.

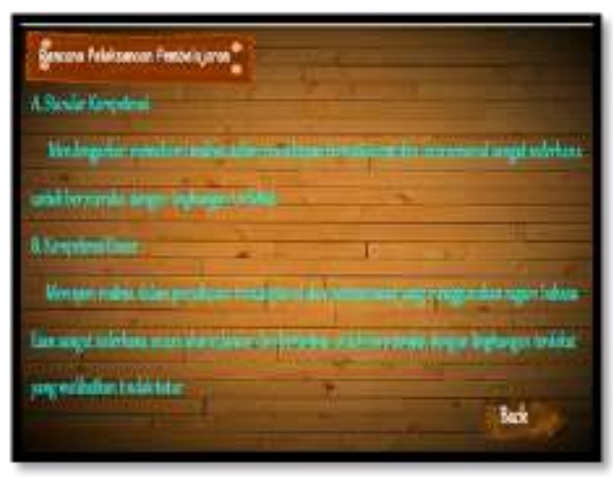

Gambar 24. menu RPP

\subsubsection{Halaman Menu Materi}

Halaman menu materi ini berisi tentang materi reading, writimg dan listening. Dapat dilihat pada gambar dibawah ini. 


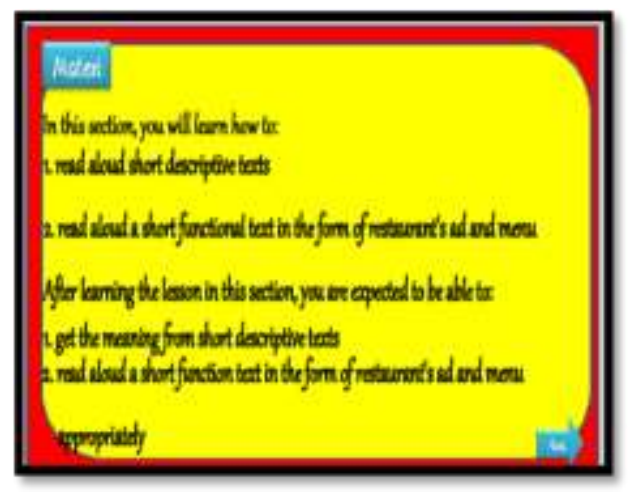

Gambar 25. menu Materi

\subsubsection{Halaman Menu Pilihan Soal}

Tampilan soal latihan ada beberapa pilihan ketika siswa akan memulai memainkannya, dapat dilihat pada gambar dibawah ini.

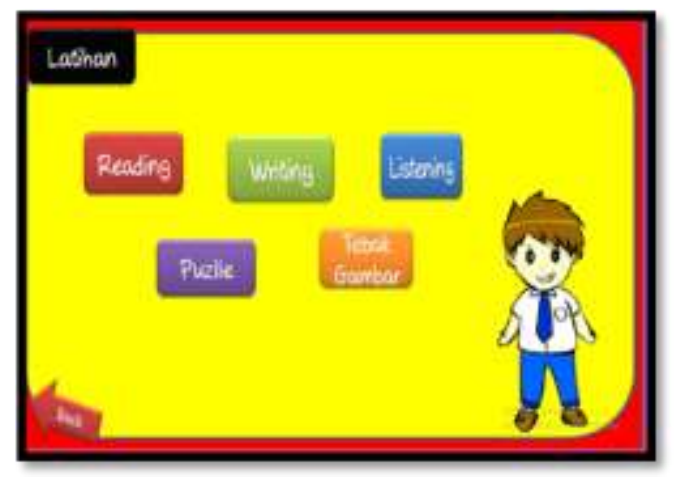

Gambar 26. Halaman Pilihan Soal

\subsubsection{Halaman Reading}

Sebelum mengerjakan soal reading harus mengisi nama, dapat dilihat gambar dibawah ini.

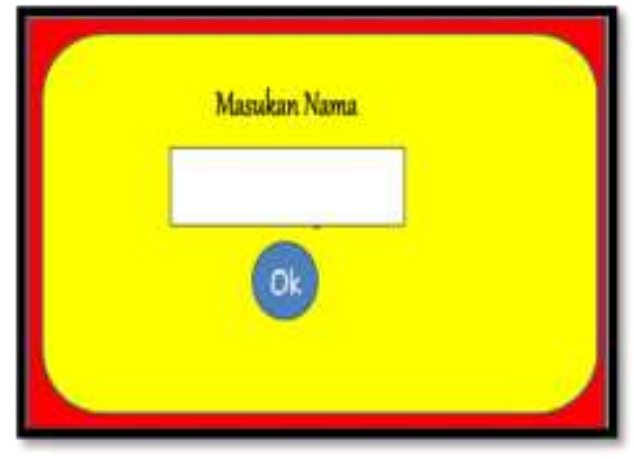

Gambar 27. Input Nama

$$
\text { Pada tampilan menu soal }
$$

Reading. Didalam menu soal yang berbentuk pilihan ganda.

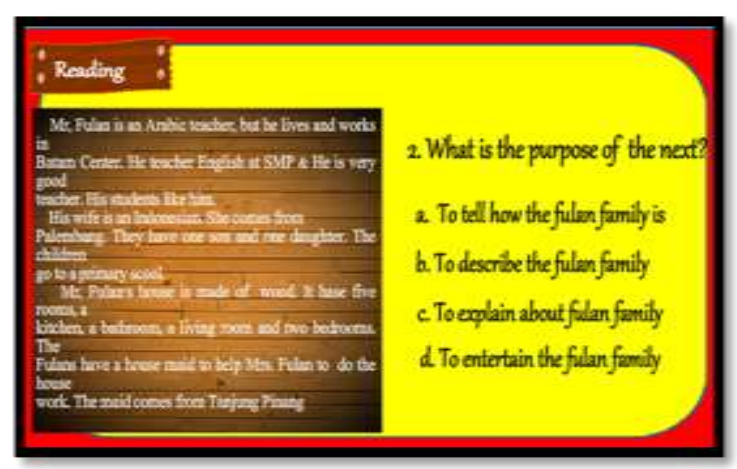

Gambar 28 Halaman Soal Reading

\section{SIMPULAN}

Dengan adanya pembuatan multimedia pembelajaran Bahasa Inggris pada SMP Negeri 8 Pagaralam berbasis multimedia menggunakan adobe cs 6, sangat mungkin diperoleh multimedia pembelajaran yang modern dan menarik. Dari penelitian yang dilakukan pada sistem pembelajaran SMP Negeri 8 Pagaralam maka penulis membuat kesimpulan sebagai berikut :

1. Penelitian ini menghasilkan multimedia pembelajaran Bahasa Inggris pada SMP Negeri 8 Pagar alam.

2. Multimedia Pembelajaran Bahasa Inggris dibuat untuk memudahkan siswa-siswi, dan guru untuk melakukan kegiatan belajar mengajar disekolah maupun di luar. 


\section{DAFTAR RUJUKAN}

Anjaya, T. (2013). Pengembangan Media Pembelajaran Pneumatik Dan Hidrolik Berbasis Adobe Flash CS6 Program Studi Diploma 3 Teknik Otomatif

Fitriyah \& Busran (2015), Perancangan Permainan (Game) Edukasi Belajar Membaca Pada Anak Prasekolah Berbasis Smartphone Android. Teknik Informatika. Fakultas Teknologi Industri Institut Teknologi Padang.

Ghea Putri Fatma Dewi (2012). Pengembangan

Game Edukasi Pengenalan Nama Hewan

Dalam Bahasa Inggris Sebagai Media Pembelajaran Siswa SD Berbasis Macromedia Flash. Prodi Pendidikan Teknik Informatika, Fakultas Teknik. Universitas Negeri Yogyakarta

Novaliandry Dony (2013). Aplikasi Game Geografi Berbasis Multimedia Interaktif (Studi Kasus Siswa Kelas IX SMPN 1 Rao)

Prof.Dr.Sugiyono (2016), Metode Penelitian Kombinasi Mixed Methods. Alfabeta, Bandung.

Radi Arizal (2011), Education Game Bahasa Inggris Untuk Anak-Anak Usia 4-12 Tahun. Universitas Bina Darma.

Raharjo Nathania (2013), Pembuatan Game Kecerdasan Verbal-Visual Untuk Siswa Tk-B. Teknik Informatika . Fakultas Teknik Universitas Surabaya.

Rinaldo (2015), Perancangan dan Implementasi e-learning pada SMA Muhammadiyah
Jarai Berbasis Web. Teknik Informatika.

Sekolah Tinggi Teknologi Pagaralam.

Rohwati.M (2012), Penggunaan Education Game Untuk Meningkatkan Hasil Belajar Ipa Biologi Konsep Klasifikasi Makhluk Hidup. Prodi Pendidikan IPA FMIPA UNNES Semarang. http://journal.unnes.ac.id/index.php/jpii

Rosa \& M.Shalahuddin (2014) ,Rekayasa Perangkat Lunak Terstruktur dan Berorientasi Objek. Informatika Bandung, Bandung.

Sukandi andi (2013) Education Game Pembelajaran Bahasa Inggris pada SMA PGRI Pagaralam. Teknik Informatika. Sekolah Tinggi Teknologi Pagaralam.

Sulviana Evi, dkk (2010), Rancang Bangun Edugame Pembelajaran Kesehatan Gigi Untuk Anak-Anak Berbasis Unity 3D. Prodi Teknik Informatika, STMIK, Palembang.

Sutopo Hadi Ariesto (2003), Multimedia Interaktif dengan Flash. Ghala ilmu

Suyanto.M (2005), Multimedia Alat untuk Meningkatkan Keunggulan Bersaing. Andi Yogyakarta. 